\title{
The antitumor effects of IFN- $\alpha$ are abrogated in a STAT1-deficient mouse
}

\author{
Gregory B. Lesinski, ${ }^{1}$ Mirela Anghelina, ${ }^{2}$ Jason Zimmerer, ${ }^{1}$ Timothy Bakalakos, ${ }^{2}$ \\ Brian Badgwell, ${ }^{2}$ Robin Parihar, ${ }^{3}$ Yan Hu, ${ }^{2}$ Brian Becknell, ${ }^{1}$ Gerard Abood, ${ }^{2}$ \\ Abhik Ray Chaudhury, ${ }^{4}$ Cynthia Magro, ${ }^{4}$ Joan Durbin, ${ }^{3,5}$ and William E. Carson III ${ }^{1,2,3}$ \\ ${ }^{1}$ Department of Human Cancer Genetics, \\ ${ }^{2}$ Department of Surgery, \\ ${ }^{3}$ Department of Molecular Virology, Immunology, and Medical Genetics, and \\ ${ }^{4}$ Department of Pathology, Arthur G. James Cancer Hospital and Richard J. Solove Research Institute, \\ The Ohio State University, Columbus, Ohio, USA \\ ${ }^{5}$ Department of Pediatrics, Children's Hospital, Columbus, Ohio, USA
}

IFN- $\alpha$ activates the signal transducer and activator of transcription (STAT) family of proteins; however, it is unknown whether IFN- $\alpha$ exerts its antitumor actions primarily through a direct effect on malignant cells or by stimulating the immune system. To investigate the contribution of STAT1 signaling within the tumor, we generated a STAT1-deficient melanoma cell line, AGS-1. We reconstituted STAT1 into AGS-1 cells by retroviral gene transfer. The resulting cell line (AGS-1 ${ }^{\text {STAT1 }}$ ) showed normal regulation of IFN- $\alpha$-stimulated genes (e.g., H2k, ISG-54) as compared with AGS-1 cells infected with the empty vector (AGS-1 ${ }^{\mathrm{MSCV}}$ ). However, mice challenged with the AGS-1, AGS-1 ${ }^{\mathrm{STAT} 1}$, and AGS-1 ${ }^{\mathrm{MSCV}}$ cell lines exhibited nearly identical survival in response to IFN- $\alpha$ treatment, indicating that restored STAT1 signaling within the tumor did not augment the antitumor activity of IFN- $\alpha$. In contrast, STAT1 ${ }^{-/-}$mice could not utilize exogenous IFN- $\alpha$ to inhibit the growth of $S T A T 1^{+/+}$melanoma cells in either an intraperitoneal tumor model or in the adjuvant setting. The survival of tumor-bearing $S T A T 1^{-1-}$ mice was identical regardless of treatment (IFN- $\alpha$ or PBS). Additional cell depletion studies demonstrated that NK cells mediated the antitumor effects of IFN- $\alpha$. Thus, STAT1-mediated gene regulation within immune effectors was necessary for mediating the antitumor effects of IFN- $\alpha$ in this experimental system.

J. Clin. Invest. 112:170-180 (2003). doi:10.1172/JCI200316603.

\section{Introduction}

IFN- $\alpha$ has been used extensively in the treatment of metastatic melanoma and mediates the regression of advanced disease in $15-20 \%$ of patients when it is administered at high doses $(1,2)$. IFN- $\alpha$ has also proven to be an effective adjuvant to surgical resection of high risk lesions (e.g., tumors involving the regional lymph nodes or measuring more than $4 \mathrm{~mm}$ in Breslow thickness) (3). Despite these findings, it remains unclear whether IFN- $\alpha$ mediates its antitumor effects through stimulation of the host immune system, by a direct effect upon

Received for publication August 6, 2002, and accepted in revised form April 29, 2003.

Address correspondence to: William E. Carson III, Division of Surgical Oncology, The Ohio State University, N924 Doan Hall, $410 \mathrm{~W} 10$ th Avenue, Columbus, Ohio 43210, USA.

Phone: (614) 293-6306; Fax: (614) 688-4366;

E-mail: carson-1@medctr.osu.edu.

Conflict of interest: The authors have declared that no conflict of interest exists.

Nonstandard abbreviations used: signal transducer and activator of transcription (STAT); interferon-stimulated gene factor 3 (ISGF3); interferon regulatory factor 9 (IRF9); interferonstimulated response element (ISRE); electrophoretic mobility shift assay (EMSA); murine stem cell virus (MSCV); long terminal repeats (LTRs); internal ribosomal entry signal (IRES); enhanced green fluorescent protein (EGFP); Moloney murine leukemia virus (M-MLV); vesicular stomatitis virus (VSV); peritoneal exudate cells (PECs). the tumor cell, or both (4). In the host, IFN- $\alpha$ has distinct immunomodulatory actions that may provide an important link between the innate and adaptive immune responses (5). IFN- $\alpha$ also exerts direct effects on tumor cells. It is a potent inhibitor of proliferation in vitro and strongly upregulates tumor cell expression of MHC class I antigens and adhesion molecules such as ICAM- 1 and L-selectin $(6,7)$. It has also been demonstrated that IFN- $\alpha$ effectively inhibits the release of tumor-derived, proangiogenic factors such as $\operatorname{bFGF}(8,9)$. Since therapy with IFN- $\alpha$ can be time consuming and complicated by severe toxicities (3), it is desirable to identify specific molecular targets within immune effectors and/or malignant cells that contribute to its antitumor activity.

The binding of IFN- $\alpha$ to its receptor activates two receptor-associated Janus family kinases, Jak1 and Tyk2, which phosphorylate the cytoplasmic tails of the interferon receptor subunits IFNAR-1 and IFNAR-2 on specific tyrosine residues. These phosphotyrosine residues provide docking sites for latent cytoplasmic transcription factors belonging to the signal transducer and activator of transcription (STAT) family of proteins, which are phosphorylated after ligand binding $(10,11)$. IFN- $\alpha$ signaling leads to formation of a DNA binding complex known as the interferon-stimulated gene factor 3 (ISGF3), which consists of STAT1- $\alpha$ (or STAT1- $\beta$, an inactive form), STAT2, and a p48 DNA 
binding protein known as interferon regulatory factor 9 (IRF9) (12). ISGF3 initiates transcription of IFN-sensitive genes through its interaction with a shared promoter element, the interferon-stimulated response element (ISRE) (13). Several studies have shown that the antitumor activity of innate and specific immune effectors (e.g., NK cells and T cells) is strongly modulated by IFN- $\alpha$ and its downstream signaling pathways $(14,15)$.

The fact that IFN- $\alpha-$ resistant cell lines frequently exhibit defects in Jak-STAT signaling and the observation that STAT1-deficient $\left(S T A T 1^{--}\right)$mice manifest severe immune deficiencies suggested to us that the antitumor effects of IFN- $\alpha$ might proceed through multiple mechanisms. To investigate the contribution of STAT1-mediated gene regulation within the tumor cell, we examined the antitumor effects of IFN- $\alpha$ in normal mice bearing STAT1-deficient murine melanoma cell lines. To investigate the role of STAT1-mediated gene regulation within the host, we compared the antitumor effects of IFN- $\alpha$ in $S T A T 1^{-/-}$and $S T A T 1^{+/+}$mice bearing STAT1-competent melanoma cell lines. We found that reconstitution of STAT1 signal transduction in a STAT1-deficient melanoma cell line did not increase the antitumor effects of IFN- $\alpha$ in a normal host. In contrast, $S T A T 1^{-/-}$mice bearing the STAT1-competent B16 murine melanoma cell line derived no survival benefit from the administration of IFN- $\alpha$. These results indicated that the antitumor effects of IFN- $\alpha$ could not proceed in the absence of STAT1 signal transduction within host tissues.

\section{Methods}

Reagents and cell lines. Murine IFN- $\alpha$ (specific activity, $3.3 \times 10^{6} \mathrm{U} / \mathrm{mg}$, Access Biochemical, San Diego, California, USA) was administered though the intraperitoneal route at a dose of $2 \times 10^{4} \mathrm{U}$ per day. Cytokine reagents contained less than $0.015 \mathrm{EU} / \mathrm{ml}$ endotoxin as measured by the E-Toxate system (Sigma-Aldrich, St. Louis, Missouri, USA). NK cells were depleted through intraperitoneal administration of an anti-asialo GM1 $\mathrm{Ab}$ (Wako BioProducts, Richmond, Virginia, USA) every 3 days beginning 2 weeks before injection of cytokines (0.2 mg per injection) (16). We have previously demonstrated that this technique results in the depletion of over $97 \%$ of NK cells in the peripheral blood and spleen as measured by flow cytometric analysis with a phycoerythrin-labeled (PE-labeled) pan-NK Ab (16). The murine melanoma cell lines B16F1 (parental line) and B16F10 (metastatic variant) were grown as adherent monolayers in RPMI-1640 media supplemented with $10 \%$ FCS and antibiotics (17). The murine melanoma cell line JB/MS was obtained from Vincent Hearing (National Cancer Institute, Bethesda, Maryland, USA) and grown as an adherent monolayer in DMEM supplemented with $10 \%$ FCS, sodium bicarbonate, $4 \mathrm{mM}$ L-glutamine, $1 \%$ vitamins, $1 \%$ sodium pyruvate, $1 \%$ nonessential amino acids, and antibiotics (18).

Animals. STAT1/- mice (C57BL/6 background) were generated by homologous recombination as previously described and housed in a pathogen-free environment (19). C57BL/6 mice and C.B-17 scid/scid (SCID) mice (C57BL/6 background) were purchased from Taconic Farms Inc. (Germantown, New York, USA) (20). All experiments were performed in compliance with the laws and guidelines of the Institutional Laboratory Animal Care and Use Committee of The Ohio State University.

Induction of the STAT1 ${ }^{-1-}$ tumor cell line AGS-1. The dorsal area of 6-day-old $S T A T 1^{-/-}$mice was treated with a $0.4 \%$ solution of 7,12-dimethylbenz[a]anthracene (Sigma-Aldrich) for 2 weeks as described (17). After a 2week rest, mice were treated with croton oil diluted to $2.5 \%$ in acetone (Sigma-Aldrich). Once nevi were visible (12-14 weeks), mice were exposed to ultraviolet light $(302 \mathrm{~nm})$ for 10-minute intervals three times per week. Tumors were harvested and digested in collagenase solution as described (17). Tumor phenotype was confirmed by histologic analysis after hematoxylin and eosin staining and immunohistochemistry for HMB-45, vimentin, and S-100. Absence of STAT1 protein and STAT 1 activation in response to IFN- $\alpha$ in the AGS- 1 cell line was confirmed by immunoblot analysis and the electrophoretic mobility shift assay (EMSA) (see below).

EMSA. Activation of STAT 1 by IFN- $\alpha$ in the AGS-1 cell line was evaluated by EMSA. Whole-cell extracts were prepared and analyzed as previously described by Sadowski et al. (21). A double-stranded oligonucleotide with affinity for activated murine STAT1 (5'-GATCCGATTCCGGGAATCA-3') served as an indicator for the DNA binding of phosphorylated STAT1 (22). Oligonucleotides were end labeled using T4 kinase and $\left[{ }^{32} \mathrm{P}\right] \mathrm{dATP}$. Wholecell extracts were preincubated in $20 \mu$ l of reaction buffer (50 mM HEPES [pH 7.9], $250 \mathrm{mM} \mathrm{KCl,} 5$ mM EDTA, 25 $\mathrm{mM} \mathrm{MgCl}_{2}, 50 \%$ glycerol, $25 \mathrm{mM}$ dithiothreitol, and 5 $\mathrm{mg} / \mathrm{ml} \mathrm{BSA}$ ) containing $5 \mu \mathrm{g}$ of poly(dI-dC) for $15 \mathrm{~min}$ utes on ice. Labeled probe $(20,000 \mathrm{cpm})$ was then added, and the reaction was continued for 15 minutes at room temperature. Ten microliters of the reaction mixture were loaded onto a $4 \%$ polyacrylamide gel in $0.5 \times$ Tris-borate EDTA buffer and electrophoresed at $120 \mathrm{~V}$. The radioactive pattern was visualized by overnight autoradiography.

Reconstitution of STAT1 into AGS-1 cells. STAT1 signaling was restored in the AGS-1 cell line by transduction with a murine stem cell virus-based (MSCV-based) retroviral vector as previously described (23). The genome of this virus contains $5^{\prime}$ and $3^{\prime}$ long terminal repeats (LTRs), a multiple cloning site, and an internal ribosomal entry signal (IRES) followed by the enhanced green fluorescent protein (EGFP) coding region. A plasmid containing the STAT1 coding sequence was obtained from $\mathrm{M}$. Holtzman (St. Louis, Missouri, USA) (24). The STAT1 sequence was excised with SacII, blunted with Klenow fragment DNA polymerase, and digested with BamHI to generate a sticky end $5^{\prime}$ to the STAT1 coding sequence. This strategy permitted the directional cloning of the STAT1 sequence into the BamHI/HpaI-digested MSCV retroviral genome. The genes encoding STAT1 and EGFP are expressed as a single transcript but are translated separately. To generate retroviral supernatants, 
293 T cells were transiently transfected by calcium phosphate-mediated coprecipitation as previously described (25). Briefly, $1.5 \times 10^{7} 293 \mathrm{~T}$ cells plated overnight in $15-\mathrm{cm}$ dishes with polylysine (SigmaAldrich) were cotransfected with plasmids encoding the gag and pol proteins from the Moloney murine leukemia virus (M-MLV) $(25 \mu \mathrm{g})$, coat proteins from the vesicular stomatitis virus (VSV) $(5 \mu \mathrm{g})$, and the STAT1-IRES-EGFP construct or a control construct (MSCV) lacking the STAT1 sequence $(25 \mu \mathrm{g})$. The retroviral supernatant was harvested at 48 hours after transfection, filtered (0.2 micron), and frozen at $-70^{\circ} \mathrm{C}(23)$. AGS-1 cells for infection were washed, trypsinized, seeded in a 6 -well plate at $2 \times 10^{5}$ cells per well, and allowed to adhere overnight. For infection, the culture medium was removed, and $1 \mathrm{ml}$ of thawed retroviral supernatant was added per well in the presence of polybrene $(8 \mu \mathrm{g} / \mathrm{ml}$ final concentration). Plates were spun for 1 hour at $1,000 \times g$, incubated overnight at $37^{\circ} \mathrm{C}$ with $5 \% \mathrm{CO}_{2}$, and supplemented with new media the next day. Cells were assayed 48 hours after infection by flow cytometric analysis for EGFP expression using uninfected AGS-1 cells for comparison. EGFP-positive cells were sorted into a 96-well plate as single cell clones (Becton Dickinson FACS Vantage SE with CLONECYT single-cell deposition system for microtiter plates; BD Biosciences Immunocytometry Systems, San Jose, California, USA). The resulting cell lines were designated AGS-1 ${ }^{\text {STAT1 }}$ and AGS-1 ${ }^{\mathrm{MSCV}}$, respectively.

a
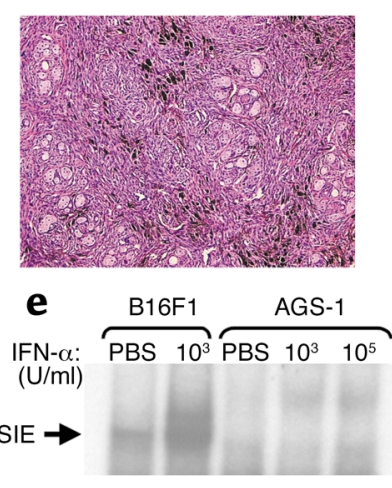

b
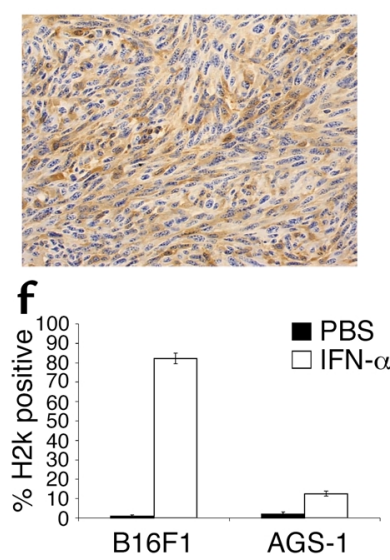

Immunoblot analysis. Cell lysates from AGS-1, AGS-1 1 TAT1, or AGS-1 $1^{\mathrm{MSCV}}$ cells (cultured in RPMI-1640 media supplemented with $10 \%$ FCS and antibiotics at $5 \%$ $\mathrm{CO}_{2}$ ) were quantitated, equally loaded, separated by SDS-PAGE, and transferred to nitrocellulose. Nitrocellulose sheets were incubated with either a murine anti-STAT1 Ab (Becton Dickinson Transduction Laboratories, Franklin Lakes, New Jersey, USA) or a rabbit $\mathrm{Ab}$ specific for the phosphorylated (activated) form of STAT1 (anti-P-STAT1) (Cell Signaling Technology Inc., Beverly, Massachusetts, USA), followed by incubation with the appropriate HRP-conjugated secondary $\mathrm{Ab}$ (Becton Dickinson Transduction Laboratories). Immune complexes were detected through the enhanced chemiluminescence reaction (Amersham Biosciences, Piscataway, New Jersey, USA). Cell lysates from A451 and B16F1 cells were used as positive controls for STAT1 expression. Cell lysates from B16F1 cells stimulated with $10^{4} \mathrm{U} / \mathrm{ml}$ of muIFN- $\alpha$ were used as a positive control for STAT1 activation.

Proliferation assay. The murine melanoma cell lines $\mathrm{B} 16 \mathrm{~F} 1, \mathrm{JB} / \mathrm{MS}$, and AGS-1 were plated in a 96-well plate and cultured for 18 hours in medium alone or medium supplemented with various concentrations of muIFN- $\alpha\left(10^{1}-10^{5} \mathrm{U} / \mathrm{ml}\right)$. Proliferation was measured by the MTT Cell Proliferation Assay as directed by the manufacturer (American Type Culture Collection, Manassas, Virginia, USA).

Flow cytometric analysis of STAT1 and phosphorylated STAT1. Phosphorylation of STAT1 in B16F1, and

c
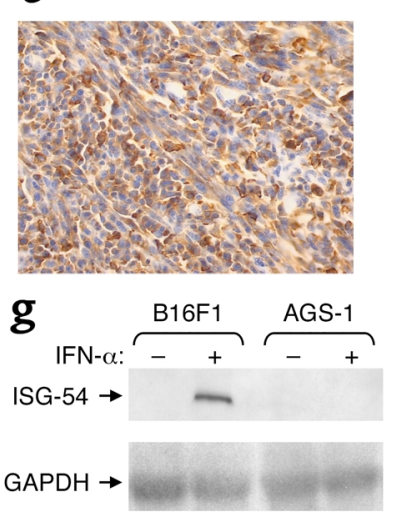

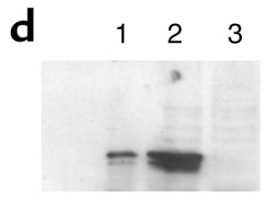

h

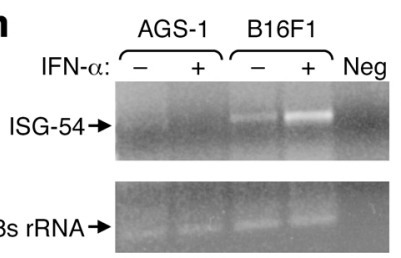

\section{Figure 1}

Characterization of the AGS-1 cell line. AGS-1 has the appearance of a malignant melanoma by (a) hematoxylin and eosin staining and immunohistochemistry for (b) S-100 and (c) HMB-45. (d) Immunoblot analysis confirmed that the AGS-1 cell line was STAT1 deficient (lane 3). Cell lysates from the A431 cell line (lane 1) and B16F1 cell line (lane 2) were used as positive controls. The protein content of the lysates was quantitated, and equal amounts were loaded onto the gel. (e) EMSA analysis revealed no activation of STAT1 in IFN- $\alpha$-treated AGS-1 cells. Lysates from IFN- $\alpha$-stimulated B16F1 cells were used as positive controls in this assay. SIS, SIS-inducible element. (f) Flow cytometric analysis of $\mathrm{H} 2 \mathrm{k}$ expression. Treatment of B16F1 cells for 48 hours with $10^{4} \mathrm{U} / \mathrm{ml}$ mulFN- $\alpha$ resulted in increased $\mathrm{H} 2 \mathrm{k}$ expression. Loss of STAT1 significantly reduced the induction of $\mathrm{H} 2 \mathrm{k}$ in the AGS-1 cell line after IFN- $\alpha$ treatment. The minor induction of $\mathrm{H} 2 \mathrm{k}$ expression by IFN- $\alpha$ in the AGS-1 cell line can be attributed to STAT1-independent signaling through NF-KB $(28,29)$. (g) Northern blot analysis indicated a loss of ISG-54 gene regulation in AGS- 1 cells after stimulation with $10^{4} \mathrm{U} / \mathrm{ml}$ mulFN- $\alpha$ for 16 hours. Probes specific for GAPDH (housekeeping gene) were used as controls and did not vary across samples. (h) Northern blot findings were confirmed by PCR using primers specific for mulSG-54 and showed increased ISG-54 expression only in B16F1 cells (positive control) after IFN- $\alpha$ treatment. Primers specific for $28 \mathrm{~s}$ rRNA (housekeeping gene) were used as a controls in this assay. Neg, negative control. 


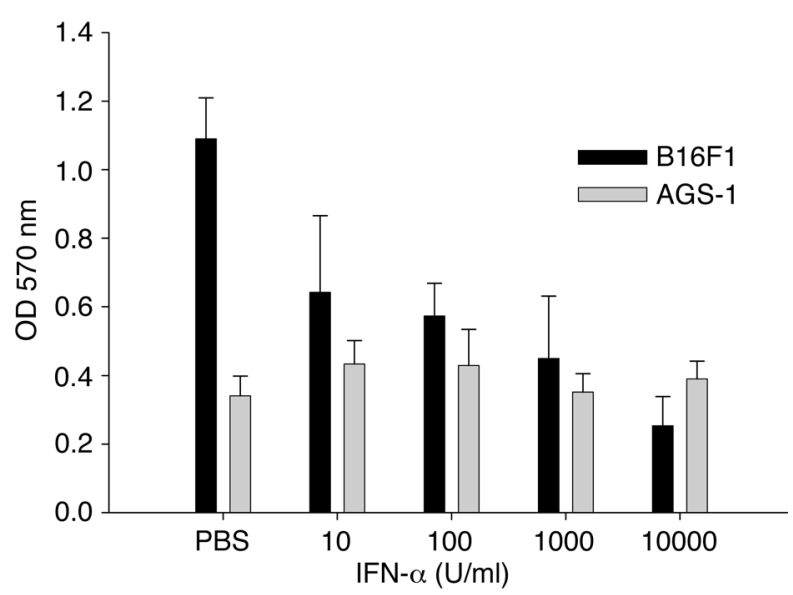

Figure 2

Antiproliferative effects of IFN- $\alpha$ in murine melanoma cell lines. Proliferation of the B16F1 and AGS-1 cell lines was measured by the MTT assay. IFN- $\alpha$ inhibits proliferation of B16F1 melanoma cells in a dose-dependent manner. In contrast, the antiproliferative effects of IFN- $\alpha$ were absent in the AGS- 1 cell line at all concentrations tested. Results represent the mean of triplicate wells and are expressed as optical density at $570 \mathrm{~nm} \pm \mathrm{SE}$.

$\mathrm{JB} / \mathrm{MS}$ tumor cells was assessed through intracellular flow cytometry (26). Briefly, $5 \times 10^{5}$ cells were suspended in $100 \mu \mathrm{l}$ of culture medium supplemented with increasing concentrations of murine IFN- $\alpha$ $\left(1-10^{5} \mathrm{U} / \mathrm{ml}\right)$ and incubated at $37^{\circ} \mathrm{C}$ for 15 minutes. Cells were then washed with cold flow buffer (PBS with $5 \% \mathrm{BSA}$ ) and fixed and permeabilized using a commercially available kit from Caltag Laboratories (Burlingame, California, USA). Upon permeabilization, cells were incubated for 30 minutes at room temperature with rabbit anti-phospho-STAT1 Ab (Cell Signaling Technology). Cells were washed with cold flow buffer and stained for 30 minutes at room temperature with $50 \mu \mathrm{l}$ of a 1:50 diluted FITC-conjugated secondary $\mathrm{mAb}$ (Biosource International, Camarillo, California, USA). Cells were then washed with cold flow buffer, fixed in $1 \%$ formalin, and analyzed by flow cytometry. Intracellular staining for total STAT1 protein was performed in a similar manner using previously established methods (26).

Flow cytometric analysis of $\mathrm{H} 2 \mathrm{k}$ expression. $\mathrm{H} 2 \mathrm{k}$ is upregulated after exposure to IFN- $\alpha$ in a STAT1dependent manner by the ISGF-3 transcription complex (27) and in a STAT1-independent manner through NF-KB $(28,29)$. Therefore, we hypothesized that loss of STAT1 would lead to reduced induction of $\mathrm{H} 2 \mathrm{k}$ after IFN- $\alpha$ treatment. $\mathrm{H} 2 \mathrm{k}$ expression was assessed in B16F1, AGS-1, AGS-1 ${ }^{\text {STAT1 }}$, and AGS-1 ${ }^{\mathrm{MSCV}}$ melanoma cells through flow cytometry using antimurine H2k FITC or PE-conjugated mAbs (Beckman Coulter, Fullerton, California, USA) after overnight stimulation with IFN- $\alpha\left(10^{4} \mathrm{U} / \mathrm{ml}\right)$.

RT-PCR. Total cellular RNA was isolated using the RNeasy kit (Qiagen, Valencia, California, USA). Firststrand cDNAs were generated by reverse transcription with random primers and used for the PCR reaction. The following primers were used: murine ISG-54 (sense, 5'-ATCAAGCGTCAAGACAAGGA-3'; antisense, 5'CATTCTTGATCCAGGAAGTGG-3') (30) and 28s rRNA (sense, 5'-TTGAAAATCCGGGGGAGA-3'; antisense, 5'ACATTGTTCCAACATGCCA-3') (31). The PCR conditions were as follows: $95^{\circ} \mathrm{C}$ for 5 minutes and then 29 cycles $\left(95^{\circ} \mathrm{C}\right.$ for 15 seconds, $66^{\circ} \mathrm{C}$ for 30 seconds, and $72^{\circ} \mathrm{C}$ for 1 minute) followed by a final extension of $72^{\circ} \mathrm{C}$ for 7 minutes. PCR products were visualized on a $1.5 \%$ agarose gel and stained with ethidium bromide under UV illumination.

Murine tumor models. An intraperitoneal model of murine malignant melanoma was used to test the effects of muIFN- $\alpha(18,32)$. Importantly, this model provides for direct contact of IFN- $\alpha$ and the tumor cells within the same body cavity, thus maximizing the direct antitumor effects of this cytokine. C57BL/6 mice were injected intraperitoneally with $10^{6}$ syngeneic melanoma tumor cells (B16F1, JB/MS, AGS-1, AGS-1 ${ }^{\text {STAT1 }}$, or AGS-1 $1^{\mathrm{MSCV}}$ ) and randomly selected to receive either PBS or muIFN- $\alpha\left(2 \times 10^{4} \mathrm{U}\right.$ per day intraperitoneally). Mice were examined daily, and those exhibiting signs of progressive disease were euthanized through $\mathrm{CO}_{2}$ inhalation. Survival experiments used at least six mice per group. The exact numbers of mice per group are given in the accompanying figure legends. A second model of malignant melanoma was used whereby locoregional lymph node metastases were generated through the subcutaneous injection of $5 \times 10^{5}$ B16F10 melanoma cells into the distal tail of C57BL/ 6 or $S T A T 1^{-/-}$mice $(n=10$ mice per group) in a volume of $0.025 \mathrm{ml}$ (33). Mice exhibited local tumor growth within 2-3 weeks, and the majority developed palpable inguinal adenopathy by 30 days. The primary tumor was resected at this point through amputation of the tail 5-10 $\mathrm{mm}$ distal to the base. Beginning the next day, mice received muIFN- $\alpha\left(2 \times 10^{4} \mathrm{U}\right.$ per day

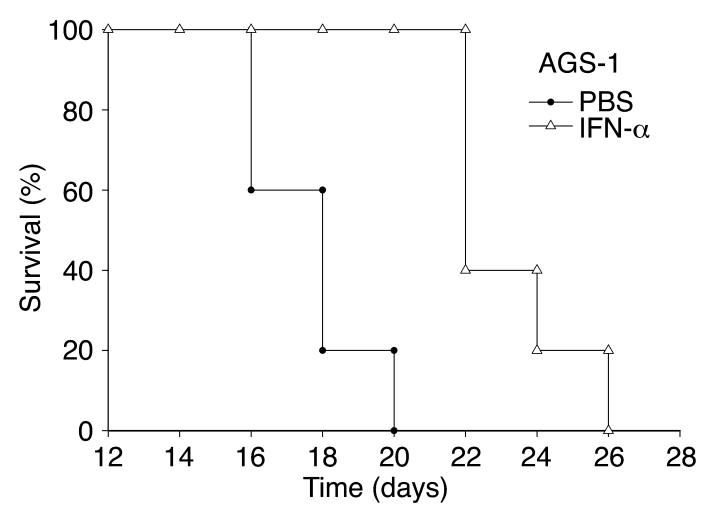

Figure 3

Survival of mice bearing the STAT1-deficient AGS-1 murine melanoma cell line. IFN- $\alpha$ treatment (open triangles) prolonged the survival of C57BL/ 6 mice ( $n=6$ mice per group) challenged with the STAT1-deficient AGS-1 melanoma cell line as compared with PBStreated mice (filled circles) $(P=0.008)$. These results are representative of two separate determinations. 

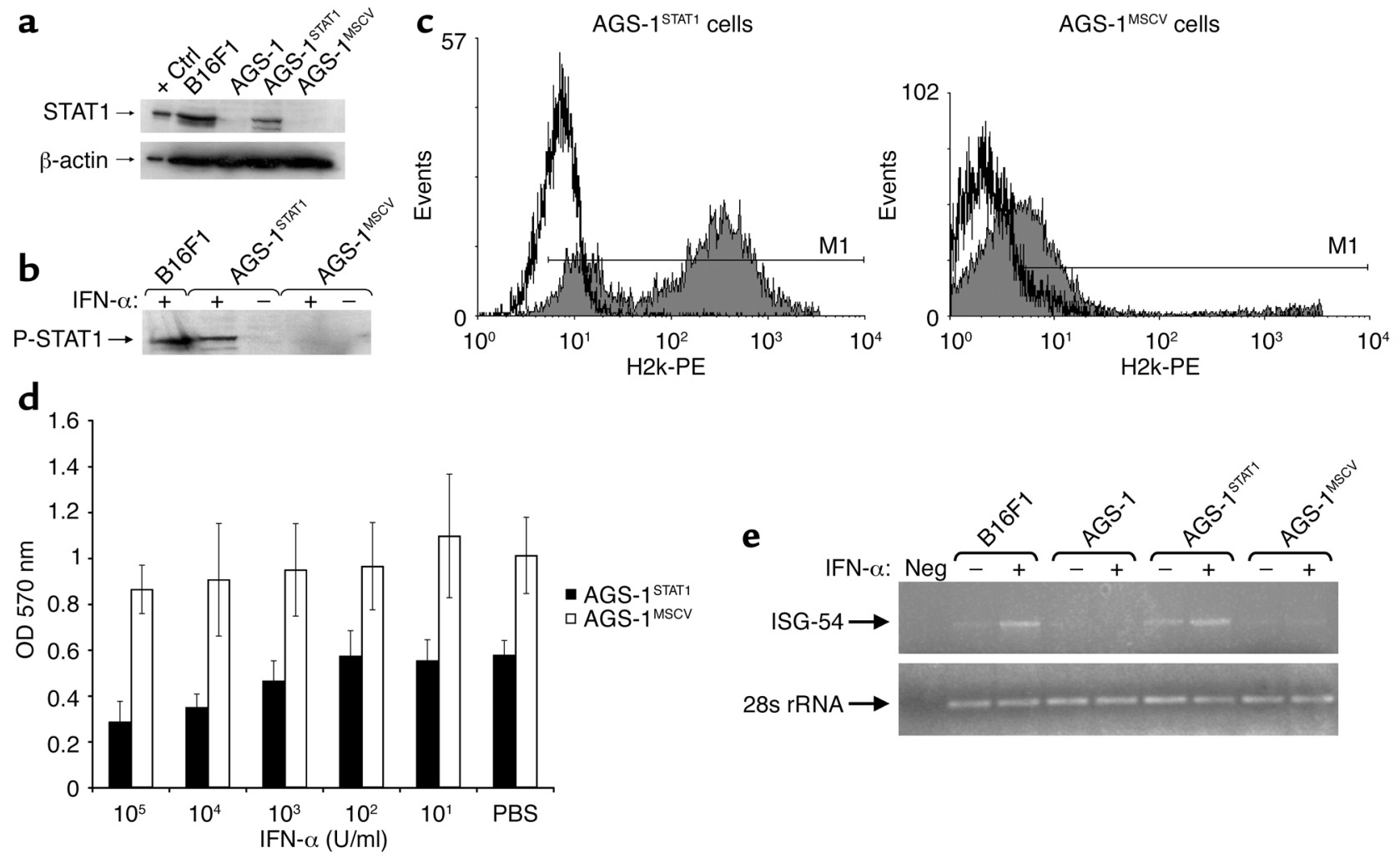

\section{Figure 4}

Reconstitution of functional STAT1 in the AGS-1 cell line. (a) Immunoblot analysis of lysates from AGS-1STAT1 cells using an anti-STAT1 antibody indicated that expression of STAT1 protein was restored. Ctrl, control. (b) The ability of STAT1 protein from AGS-1 STAT1 cells to undergo phosphorylation at Tyr-701 was confirmed by immunoblotting with an anti-P-STAT1 monoclonal antibody. (c) Overnight stimulation with IFN- $\alpha\left(10^{3} \mathrm{U} / \mathrm{ml}\right)$ resulted in enhanced $\mathrm{H} 2 \mathrm{k}$ expression on AGS-1 ${ }^{\text {TTAT1 }}$ but not AGS-1 ${ }^{\text {MSCV }}$ melanoma cells. Shaded histograms represent fluorescence intensity of $\mathrm{H} 2 \mathrm{k}-\mathrm{PE}$ staining in IFN- $\alpha$-stimulated EGFP-positive cells. White histograms represent $\mathrm{H} 2 \mathrm{k}-\mathrm{PE}$ staining in PBS-stimulated EGFP-positive cells. Determination of H2k-positive cells was based on isotype control antibodies (M1), which fell within the first log of fluorescence. (d) IFN- $\alpha$ inhibits proliferation of the AGS-1STAT1 cell line in a dose-dependent manner. In contrast, the antiproliferative effects of IFN- $\alpha$ were not evident in AGS-1 ${ }^{\text {MSCV }}$ cells. Results represent the mean of triplicate wells and are expressed as optical density at $570 \mathrm{~nm} \pm \mathrm{SE}$. (e) The ability of the AGS-1 ${ }^{\text {STAT1 }}$ cell line to regulate ISGF3 gene transcription in response to IFN- $\alpha$ was confirmed by PCR. Total cellular RNA was isolated from cell lines (B16F1, AGS-1, AGS-1STAT1, and AGS-1 MSCV ) after overnight treatment with $10^{4} \mathrm{U} / \mathrm{ml}$ of murine IFN- $\alpha$ and converted to cDNA using standard methods. PCR primers specific for mulSG-54 detected increased ISG-54 expression in only the B16F1 (positive control) and AGS-1 ${ }^{\text {STAT1 }}$ cell lines after IFN- $\alpha$ treatment. Primers specific for $28 \mathrm{~s}$ rRNA (housekeeping gene) were used as controls.

intraperitoneally) or PBS daily. Survival was measured from the time of tumor resection.

Histochemical analysis of murine tumors. C57BL/6 mice and STAT1-deficient mice were injected intraperitoneally with $10^{6} \mathrm{~B} 16$ cells and given daily treatments of muIFN- $\alpha\left(2 \times 10^{4} \mathrm{U}\right.$ per day) or PBS (control). Tumors were harvested at 7 days or 10 days, fixed in formalin solution, and embedded in paraffin. Sections $(5 \mu \mathrm{m})$ were stained with hematoxylin and eosin and examined under a light microscope. The sections were examined and scored for proliferative index and the presence of immune cell infiltrates. The examiner was unaware of the identity of each sample.

Flow cytometric detection of peritoneal exudate cells. Peritoneal lavage of C57BL/ 6 mice ( $n=5$ per group) bearing B16 tumors was performed on day 7 after daily treatment with IFN- $\alpha\left(2 \times 10^{4} \mathrm{U}\right.$ per day $)$ or PBS. Peritoneal exudate cells (PECs) from each mouse were collected with sterile PBS; stained with a PEconjugated anti-DX5, an APC-conjugated anti-CD3, or an appropriate isotype control antibody (BD Parmingen, San Diego, California, USA); and analyzed for the presence of $\mathrm{NK}$ and $\mathrm{T}$ cells by flow cytometry.

Cytotoxicity assays and IFN- $\gamma$ ELISA. Murine splenocytes were isolated from C57BL/6 mice and STAT1 ${ }^{-/-}$mice and used as effectors against the YAC- 1 murine cell lines in a standard 4-hour ${ }^{51} \mathrm{Cr}$-release assay (34). A separate assay was run using splenocytes stimulated in vitro with $10^{4} \mathrm{U} / \mathrm{ml}$ of IFN- $\alpha$ for 18 hours as effectors against the B16F1 melanoma cell line.

Statistical analysis. Since survival data were not censored, the nonparametric Mann-Whitney U test was used to compare treatment groups on the basis of survival, with a two-sided $P$ of less than 0.05 considered statistically significant.

\section{Results}

Characterization of a STAT1-deficient murine melanoma cell line AGS-1. A cell line (AGS-1) was generated in STAT1-/mice. A melanotic phenotype was confirmed through 
a

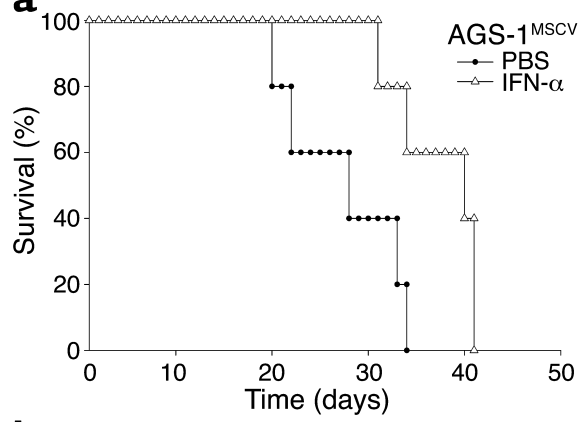

b

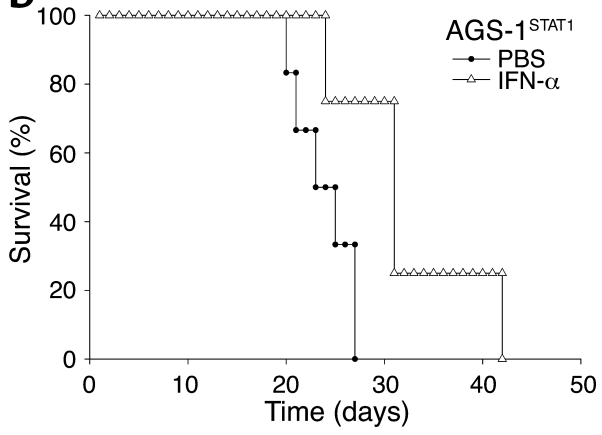

light microscopy and immunohistochemistry for HMB-45, vimentin, and S-100 (Figure 1, a-c, and data not shown). Immunoblot, electrophoretic gel shift, and flow cytometric analysis revealed that this cell line does not express STAT1 or respond to IFN- $\alpha$ treatment with the formation of an ISGF3 complex (Figure 1, $d$ and e, and data not shown). To evaluate whether ISGF3 target genes were activated in this cell line after IFN- $\alpha$ treatment, $\mathrm{H} 2 \mathrm{k}$ expression was evaluated by flow cytometry (Figure 1f), and ISG-54 expression was evaluated by Northern blot and RT-PCR analysis (Figure 1, $\mathrm{g}$ and $\mathrm{h}$ ). These data demonstrate that the AGS-1 cell line fails to regulate the expression of IFN-stimulated genes in response to IFN- $\alpha$.

Antiproliferative effects of IFN- $\alpha$ in a STAT1-deficient melanoma cell line. The antiproliferative effects of IFN- $\alpha$ on the AGS-1 cell line were tested in vitro using the tetrazolium-based MTT assay. No significant inhibition of proliferation was observed at IFN- $\alpha$ concentrations ranging from $10^{1}-10^{5} \mathrm{U} / \mathrm{ml}$, whereas a strong antiproliferative effect was seen for the control murine melanoma cell lines B16F1 and JB/MS (Figure 2 and data not shown). The antitumor actions of IFN- $\alpha$ in a STAT1-deficient cell line. To determine if lack of STAT1 signaling within the melanoma tumor cell interfered with the antitumor actions of IFN- $\alpha$, 4- to 6 -week-old female C57BL/ 6 mice ( $n=6$ mice/group) were injected intraperitoneally with $10^{6}$ AGS- 1 tumor cells and treated daily with $2 \times 10^{4} \mathrm{U}$ per day of muIFN- $\alpha$. Control mice received injections of PBS. The mean survival of mice challenged with AGS-1 melanoma cells was significantly extended by IFN- $\alpha$ treatment $(P=0.008)$, suggesting that IFN- $\alpha$ can enhance survival in a model in which STAT1-mediated signal transduction and gene regulation are absent within the tumor (Figure 3). Importantly, these survival

\section{Figure 5}

The antitumor effects of IFN- $\alpha$ are not enhanced after reconstitution of STAT1 signaling within the melanoma cell. (a) IFN- $\alpha$ treatment (open triangles) significantly $(P<0.01)$ prolonged the survival of C57BL/ 6 mice ( $n=6$ mice per group) bearing AGS- 1 cells infected with empty vector (AGS-1 ${ }^{\mathrm{MSCV}}$ ) as compared with PBS-treated mice (filled circles). (b) IFN- $\alpha$ treatment (open triangles) also significantly $(P<0.01)$ prolonged the survival of C57BL/ 6 mice $(n=6$ mice per group) challenged with the STAT1-reconstituted AGS-1 melanoma cell line (AGS-1 STAT1 $^{\text {) }}$ as compared with PBS-treated mice (filled circles). These results are representative of two separate determinations.

data are comparable to those obtained for STAT1-competent murine melanoma cell lines such as B16F1 and JB/MS (see Figure 6, b and d).

Reconstitution of STAT1 signaling within the AGS-1 cell line. In order to more fully explore the contribution of tumor cell Jak-STAT signal transduction in mediating the antitumor effects of IFN- $\alpha$, we infected the AGS-1 cell line with a STAT1 retroviral construct to give the AGS-1 $1^{\text {STAT1 }}$ cell line. A control cell line (AGS-1 ${ }^{\text {MSCV }}$ ) was created through infection of AGS-1 cells with the empty vector $(23,25)$. The presence of STAT1 was

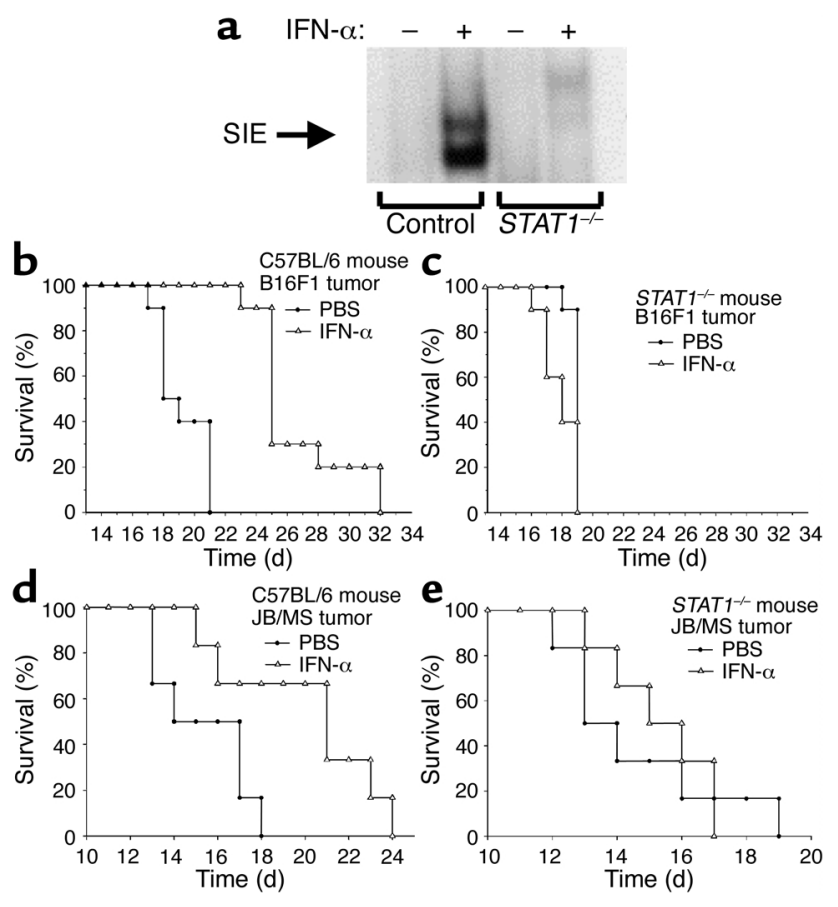

\section{Figure 6}

Absence of STAT1 in the host results in decreased signaling in response to IFN- $\alpha$ and decreased survival after tumor challenge. (a) A DNA probe specific for activated murine STAT1 reacted with whole-cell lysates from IFN- $\alpha$-treated splenocytes of C57BL/ 6 but not STAT1-deficient mice. Similar results were obtained in other tissues, including liver and kidney (data not shown). STAT1-1- and C57BL/ 6 mice ( $n=10$ mice per group) were injected intraperitoneally with $10^{6} \mathrm{~B} 16 \mathrm{~F} 1$ melanoma cells. As compared with PBS-treated controls (filled circles), IFN- $\alpha$ treatment $\left(2 \times 10^{4} \cup\right.$ per day) (open triangles) prolonged the survival of C57BL/ 6 mice but not STAT1-/mice challenged with B16F1 melanoma cells (b and $\mathbf{c}$ ) or JB/MS melanoma cells ( $n=6$ mice per group) $(\mathbf{d}$ and $\mathbf{e})$. 


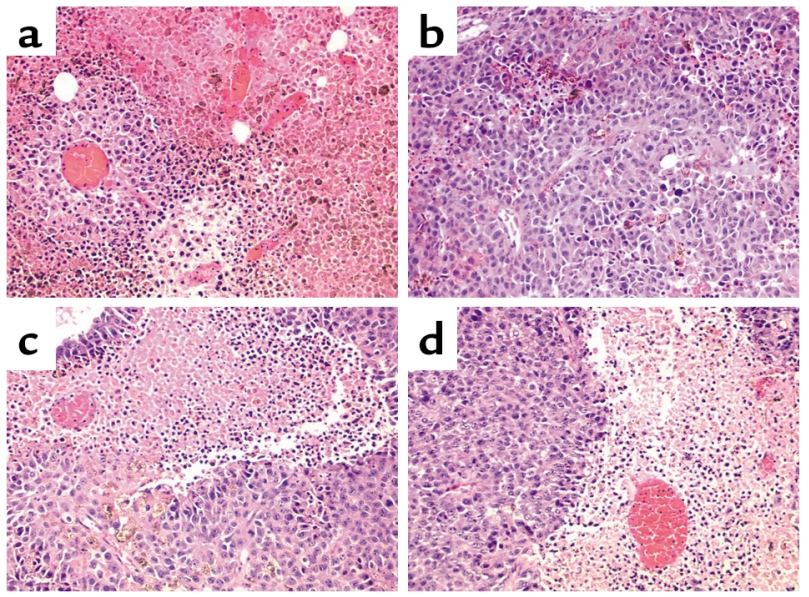

Figure 7

Histochemical analysis. B16F1 tumors from C57BL/ 6 mice treated with (a) PBS or (b) IFN- $\alpha$ and STAT1-deficient mice treated with (c) PBS or (d) IFN- $\alpha$ were stained with hematoxylin and eosin and analyzed at $\times 40$. A striking degree of tumor cell necrosis was observed in STAT1-deficient mice treated with either PBS or IFN- $\alpha$. A similar degree of necrosis was observed in PBS-treated C57BL/ 6 mice. Notably, the least degree of tumor cell necrosis was observed in $\mathrm{C} 57 \mathrm{BL} / 6$ mice treated with IFN- $\alpha$, which was the only group exhibiting prolonged survival.

confirmed in AGS-1 ${ }^{\text {STAT1 }}$ cells by immunoblot analysis (Figure 4a). Treatment of AGS-1 ${ }^{\text {STAT1 }}$ cells with IFN- $\alpha$ stimulated STAT1 signal transduction and resulted in increased $\mathrm{H} 2 \mathrm{k}$ expression, restored sensitivity to the antiproliferative effects of IFN- $\alpha$, and increased expression of the IFN-responsive gene ISG-54, whereas AGS-1 ${ }^{\mathrm{MSCV}}$ cells exhibited the STAT1 null phenotype of the parental cell line (Figure 4, b-e).

Restored STAT1 signaling in the AGS-1 cell line does not enhance the antitumor effects of IFN- $\alpha$ in vivo. To determine the effects of restoring STAT1 signaling in the AGS-1 cell line, C57BL/ 6 mice ( $n=6$ mice per group) were injected with $10^{6}$ tumor cells (AGS-1 $1^{\text {STAT1 }}$ or AGS-1MSCV) and treated daily with $2 \times 10^{4} \mathrm{U}$ of IFN- $\alpha$. Control mice received injections of PBS. Notably, the administration of IFN- $\alpha$ significantly extended the survival of mice bearing the AGS-1 ${ }^{\mathrm{MSCV}}$ cell line $(P<0.01)$, despite the absence of STAT1 signaling within the tumor (Figure $5 \mathrm{a})$. The survival of mice bearing AGS-1 $1^{\mathrm{STAT} 1}$ tumors was similarly prolonged (Figure $5 \mathrm{~b}$ ). Thus, restoration of STAT1-mediated gene regulation within the tumor did not prolong the survival of IFN-treated mice.

Effects of IFN- $\alpha$ in tumor-bearing, STAT1-deficient mice. To determine whether the antitumor actions of IFN- $\alpha$ are mediated by the induction of IFN-regulated genes within host tissues, we investigated the antitumor actions of IFN- $\alpha$ in STAT1 $1^{--}$mice. Lack of STAT1 binding activity in the STAT1-/- mice was confirmed by EMSA analysis (Figure 6a) (21). Similar results were obtained in other tissues, including liver and kidney (data not shown). $S T A T 1^{-/-}$mice and strain-matched controls were injected intraperitoneally with $10^{6}$ B16F1 melanoma cells (parental line) and then given daily injections of PBS or IFN- $\alpha$. IFN- $\alpha$ treatments did not prolong the survival of $\mathrm{STAT1}^{-/-}$mice challenged intraperitoneally with $10^{6}$ B16F1 tumor cells, nor did they alter the pattern of growth or the eventual cause of death (Figure 6, b and c). In addition, IFN- $\alpha$ treatments did not prolong the survival of STAT1 1 - mice challenged with JB/MS melanoma cells when compared with PBS treatments $(P=0.68)$ (Figure 6, $\mathrm{d}$ and e). Importantly, both the B16F1 and JB/MS cell lines are sensitive to the antiproliferative effects of IFN- $\alpha$ and respond to IFN- $\alpha$ treatment with the phosphorylation of STAT1 (Figure 2 and data not shown).

Histochemical analysis of B16F1 tumors from PBSand IFN- $\alpha$-treated normal and STAT1 $1^{-/}$mice revealed a pleomorphic epithelioid melanoma with relatively abundant cytoplasm and heterogeneous cytoplasmic melanization. Appreciable tumor necrosis was observed in all conditions by day 10 of treatment. However, IFN- $\alpha$-treated, wild-type C57BL/6 mice (which had prolonged survival) exhibited the least degree of tumor cell necrosis as compared with other treatment groups (Figure 7, a-d). One possible explanation for this observation is that tumor cell necrosis was associated with rapid tumor growth in this model. Interestingly, the number of mitoses per 10 high-power fields was twofold higher for mice receiving PBS than it was for mice receiving IFN- $\alpha$, regardless of whether the
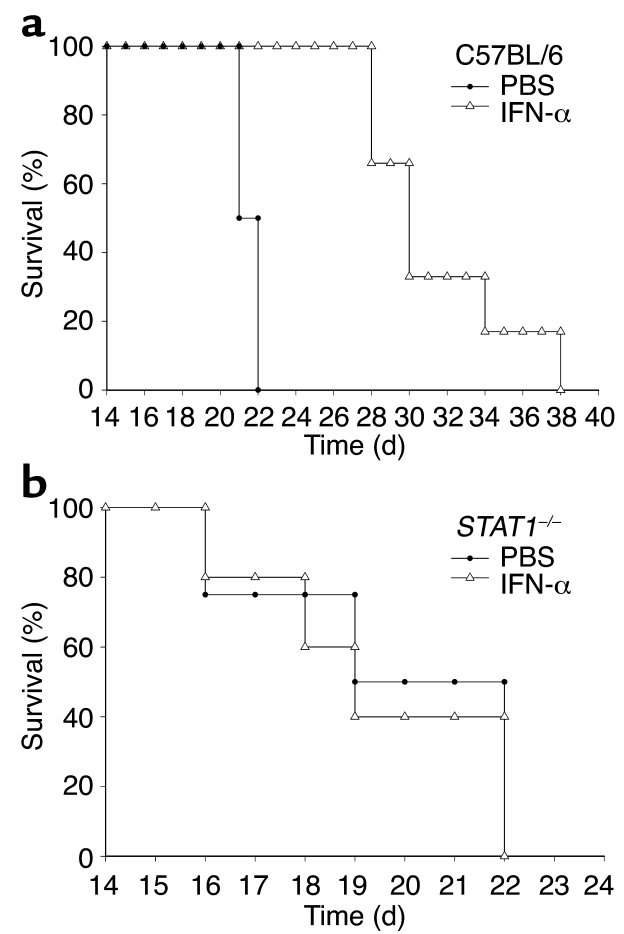

Figure 8

Effects of IFN- $\alpha$ on the survival of C57BL/ 6 and STAT1-deficient mice bearing locoregional B16F10 metastases. IFN- $\alpha$ treatment (open triangles) significantly prolonged the survival of (a) C57BL/6 mice $(P=0.002)$ but not $(b)$ STAT1-deficient mice $(P=0.73)$ bearing B16F10 locoregional metastases as compared with PBS-treated (filled circles) controls. There were 10 mice in each group. 


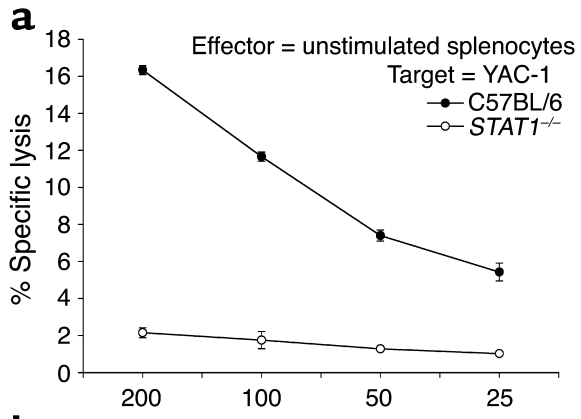

b

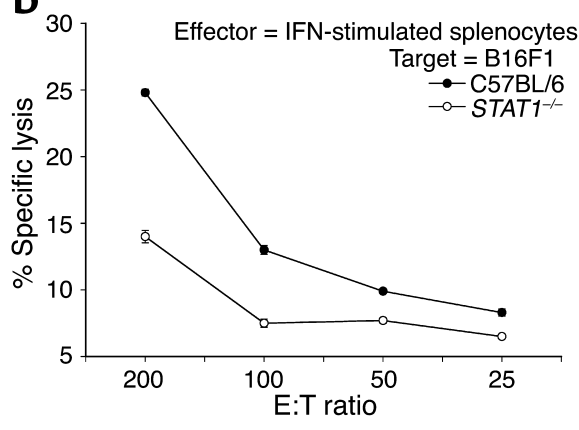

host was of the C57BL/6 or STAT1 1 -- background (data not shown). This finding suggests that the IFN- $\alpha$ treatments were able to exert their antiproliferative effects on the B16 melanoma equally well in both murine strains. Effects of IFN- $\alpha$ in a murine model of locoregional lymph node metastases. We next investigated the antitumor effects of IFN- $\alpha$ in STAT1 $1^{-/}$and C57BL/6 mice that bore locoregional lymphatic metastases after the subcutaneous injection of $5 \times 10^{5} \mathrm{~B} 16 \mathrm{~F} 10$ melanoma cells into the distal tail. Thirty days after injection, primary tumors were amputated, and mice were randomly assigned to receive either muIFN- $\alpha\left(2 \times 10^{4} \mathrm{U}\right.$ per day $)$ or control solution (PBS) (33). Treatment of tumorbearing C57BL $/ 6$ mice with IFN- $\alpha$ prolonged survival by an average of 10 days as compared with PBS-treated mice (Figure $8 a$ ). In contrast, IFN- $\alpha$ did not significantly prolong the survival of $S T A T 1^{-/-}$mice after the resection of established tail tumors associated with disease in the regional lymphatic basins (Figure $8 b)(P=0.73)$.

IFN- $\alpha$ treatment of melanoma tumors in mice depleted of $N K$ cells. Our results suggested that STAT1 signaling within

\section{Figure 10}

IFN- $\alpha$ treatment leads to increased NK cells within the PECs of mice bearing B16F1 melanoma tumors. (a) Flow cytometric analysis of PECs from C57BL/6 mice bearing B16F1 tumors revealed the presence of a significant NK cell infiltrate in IFN- $\alpha$-treated mice (shaded histogram) but not in PBS-treated mice (white histogram). (b) In contrast, CD3-positive cells were present in PECs from both PBStreated and IFN- $\alpha$-treated mice. Each analysis was performed on at least 10,000 cells gated in the region of the lymphocyte population on the basis of light scatter properties (forward scatter versus side scatter). Fluorescence data were shown on four-decade log scales, and instrument settings were adjusted in reference to PECs stained with appropriate isotype control antibodies. Each histogram is representative of PECs from five mice.

\section{Figure 9}

Deficient splenocyte cytotoxic activity in STAT1/- mice. (a) Unstimulated splenocytes from STAT1-/- mice (open circles) and wild-type C57BL/ 6 mice (filled circles) were tested for cytotoxic activity against the NK-sensitive YAC-1 cell line in a standard 4 -hour ${ }^{51} \mathrm{Cr}$ release assay. (b) Splenocytes from STAT1/- mice (open circles) and wildtype C57BL/ 6 mice (filled circles) were tested for cytotoxic activity against the B16F1 murine melanoma cell line in a standard 4-hour ${ }^{51} \mathrm{Cr}$ release assay after stimulation with $10^{4} \mathrm{U} / \mathrm{ml} \mathrm{IFN}-\alpha$ for 18 hours.

host tissues played a major role in the antitumor actions of IFN- $\alpha$ in this experimental model. Since IFN- $\alpha$ has potent effects on the NK cell compartment, we examined immune effectors from $S T A T 1^{-/-}$mice for their ability to produce immunomodulatory cytokines and mediate lysis of relevant tumor targets. Splenocyte production of immunoregulatory cytokines (e.g., IFN- $\gamma$ ) was not appreciably altered by the loss of STAT1 (data not shown). However, unstimulated STAT1 $1^{-/-}$splenocytes exhibited reduced NK cell cytotoxicity against NK-sensitive murine targets when compared with splenocytes from wild-type C57BL/6 mice (Figure 9a). When stimulated with $10^{4} \mathrm{U} / \mathrm{ml}$ IFN- $\alpha$, STAT1 $1^{-/}$splenocytes also showed reduced cytotoxicity against the B16F1 cell line (Figure $9 \mathrm{~b})$, despite having normal numbers of NK cells in the spleen and peripheral blood (35). These results suggested that NK cells from STAT1/- mice might have a reduced capacity to eliminate tumor cells in vivo.

We were therefore interested to determine whether NK cells were present within B16 tumors located in the intraperitoneal position of normal mice (36). B16F1 tumors were harvested from PBS- and IFN- $\alpha$-treated C57BL/6 mice at day 7 and analyzed for a lymphocytic infiltrate through hematoxylin and eosin staining. Tumor-infiltrating lymphocytes were infrequently observed regardless of the treatment (data not shown).
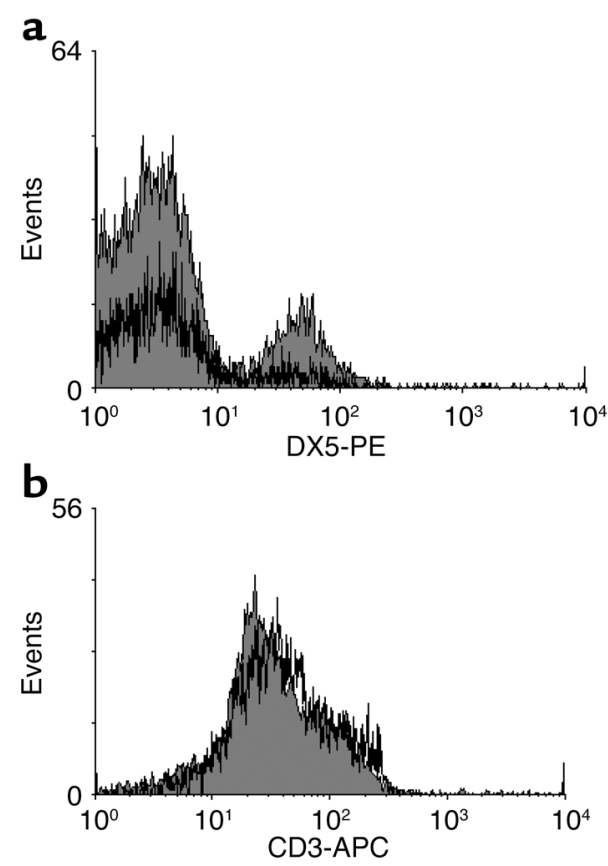

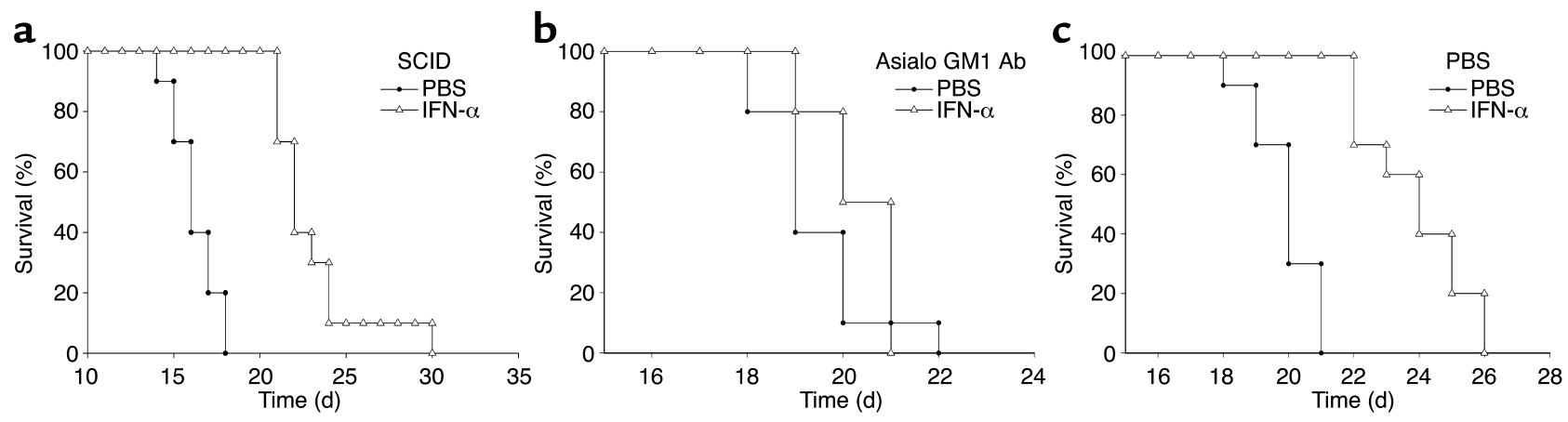

Figure 11

The antitumor effects of IFN- $\alpha$ are abrogated in NK-cell depleted SCID mice. (a) IFN- $\alpha$ treatment (open triangles) significantly prolonged the survival of SCID mice bearing B16F1 tumors in the intraperitoneal position when compared with PBS-treated (filled circles) SCID mice $(P<0.01)$. IFN- $\alpha$ treatment (open triangles) did not prolong the survival of NK cell-depleted SCID mice bearing B16F1 tumors in the intraperitoneal position (b) as compared with PBS-pretreated (filled circles) SCID mice (c). All studies using SCID mice used six mice per treatment arm.

However, flow cytometric analysis of cells contained within the peritoneal washings of tumor-bearing mice revealed high numbers of NK cells in those animals receiving IFN- $\alpha$. Few if any NK cells were observed in the washings of PBS-treated mice (Figure 10a). Of note, comparable levels of $\mathrm{CD}^{+}$cells were detected in PECs from both treatment groups (Figure 10b). Taken together, these findings suggest that NK cells are localized in proximity to the intraperitoneal tumors of animals receiving IFN- $\alpha$.

Since IFN- $\alpha$ has been shown to stimulate both the NK cell and $\mathrm{T}$ cell compartments, we conducted experiments in immunodeficient SCID mice to determine the contribution of $\mathrm{T}$ cells to the actions of IFN- $\alpha$ in this tumor model. Interestingly, tumor-bearing SCID mice exhibited significant improvement in survival in response to treatment with IFN- $\alpha$ (Figure 11a). We subsequently administered IFN- $\alpha$ to SCID mice depleted of NK cells by pretreatment with an anti-asialo GM1 Ab (Figure 11b). This treatment effectively abrogated the antitumor effects of IFN- $\alpha$ in the current model, whereas control mice exhibited prolongation of survival (Figure 11, a and c). Taken together, these data suggest that NK cells are a major cellular mediator of the antitumor actions of IFN- $\alpha$ in mice bearing the B16 melanoma.

\section{Discussion}

We have examined the role of Jak-STAT signal transduction in the antitumor actions of IFN- $\alpha$ in the setting of malignant melanoma. In the intraperitoneal challenge model, tumor cells and IFN- $\alpha$ were administered concurrently into the same body cavity to maximize the direct effect of IFN- $\alpha$. Even under these circumstances, we found that restoration of Jak-STAT signaling within the STAT1-negative AGS-1 tumor cell line did not enhance the antitumor effects of IFN- $\alpha$. In contrast, $S T A T 1^{-/-}$mice could not utilize exogenous IFN- $\alpha$ to inhibit the growth of unmodified B16F1 or JB/MS tumor cells and succumbed to their disease at exactly the same time as did PBS-treated STAT1 ${ }^{-/}$mice bearing the same tumor. Identical results were obtained in a second murine model of malignant melanoma in which a highly metastatic melanoma cell line (B16F10) was used to generate locoregional metastases in the inguinal lymph nodes of $\mathrm{STAT1}^{-/-}$mice. STAT1 ${ }^{-/-}$mice exhibited normal levels of circulating immune effector cells, but splenocytes from $S T A T 1^{-/-}$mice exhibited a reduction in cytotoxic activity against the B16 melanoma cell line and the NK-sensitive YAC-1 cell line. Indeed, mice depleted of NK cells before the injection of B16F1 melanoma cells were insensitive to the antitumor actions of IFN- $\alpha$, whereas IFN- $\alpha$ treatments remained effective in prolonging the survival of $\mathrm{T}$ cell- and B cell-deficient SCID mice bearing this tumor cell line. Analysis of IFN-treated mice revealed greater numbers of NK cells within the peritoneal exudate than in PBS-treated controls. Taken together, these data indicate that STAT1-mediated gene regulation in host tissues, specifically NK cells, is critical to the antitumor activity of IFN- $\alpha$.

The original rationale for the administration of IFN- $\alpha$ in the setting of advanced malignancy was the observation that it had profound antiproliferative effects on a variety of tumor types (37). Malignant melanoma cells routinely express functional IFN- $\alpha$ receptors and are sensitive to physiologic concentrations of this cytokine (38). We have previously shown that ex vivo treatment of patient tumors with clinically relevant concentrations of IFN- $\alpha$ consistently activated STAT 1 and STAT2 (39). These observations suggested that IFN- $\alpha$ treatments most likely exert a direct effect on tumor cells regardless of their ability to stimulate host tissues. More recently, it was observed that some IFN- $\alpha-$ resistant human melanoma cell lines exhibited defects in specific Jak-STAT intermediates, which when reversed led to the recovery of in vitro sensitivity to IFN- $\alpha$ (40-42). Interestingly, the most common defect appeared to be the loss of STAT1.

In contrast, our experiments with STAT1-negative tumor cells suggested that the antitumor effects of IFN- $\alpha$ are not appreciably enhanced after the reconstitution of STAT1 signaling in the tumor. Obviously, these results apply only to the use of IFN- $\alpha$ in the 
setting of advanced disease and to these particular cell lines in the context of the intraperitoneal model. It is entirely possible that in other experimental tumors (and human cancers for that matter) the existence of an intact Jak-STAT signaling pathway may significantly enhance the antitumor activity of IFN- $\alpha$ (43). Importantly, Kaplan et al. (42) have demonstrated the existence of an IFN- $\gamma$-dependent tumor surveillance system in immunocompetent mice. Their experiments indicated that the actions of IFN- $\gamma$ on chemically induced fibrosarcomas were mediated primarily through a direct effect on the tumor cells. The differences between this study and our own are notable. Kaplan et al. found that endogenous production of IFN- $\gamma$ was needed to activate STAT1 signal transduction within the tumors so that they would develop enhanced immunogenicity and therefore be recognized by host $T$ cells (42). In contrast, we found that exogenous IFN- $\alpha$ was required to activate STAT1 signal transduction within host NK cells so that they could mediate an antitumor effect within transplanted melanoma tumors (42). The present study does not prove that the antitumor activity of IFN- $\alpha$ never proceeds through a direct effect on tumor cells; however, it does indicate that STAT1mediated gene regulation within immune cells is required in the present experimental system.

IFN- $\alpha$ could theoretically exert a concurrent direct effect on the tumor (or the host) through the activation of alternate signaling pathways that do not employ Jak-STAT intermediates. A recent study by Gil et al. demonstrated that IFN- $\gamma$ and IFN- $\beta$ can both regulate proliferative responses in a STAT1-null murine mononuclear phagocytic cell line and that many genes are induced by IFN- $\gamma$ in the absence of STAT1 (44). It is possible that IFN- $\alpha$ may also induce specific genes in a STAT1-independent fashion (45-47). Doublestranded RNA activated serine-threonine protein kinase is activated as part of a kinase cascade leading to serine phosphorylation of STAT1, inhibition of c-myc expression, and regulation of cellular proliferation (45, $46,48)$. IFN- $\alpha$ is also capable of activating NF- $\kappa B$ and phosphatidylinositol 3-kinase signal transduction that leads to the regulation of apoptosis (28). However, if activation of STAT1-independent signaling pathways within either the host, the tumor, or the tumor microenvironment were critically important to the antitumor effects of IFN- $\alpha$ in malignant melanoma, then administration of this cytokine should have prolonged the survival of $S T A T 1^{-/-}$mice bearing the parental B16F1 or JB/MS melanoma cell lines. It could be argued that the present model does not exclude the potential antitumor effects of endogenously produced IFN- $\gamma$, which signals through a STAT1 homodimer; however, significant IFN- $\gamma$ production in response to IFN- $\alpha$ has not been observed in patient studies (49, 50 ), nor did we measure any IFN- $\gamma$ in the serum of tumor-bearing normal or STAT1-deficient mice that received IFN- $\alpha$ treatments (data not shown).
Several studies in both mice $(51,52)$ and humans $(53,54)$ suggest that NK cells are important in mediating tumor rejection, particularly in response to treatment with IFN- $\alpha$. It is also known that lymphocytes, including NK cells, may accumulate in tumor lesions at an early stage $(14,55)$. The importance of STAT1 in mediating both IFN- $\alpha$-dependent and -independent NK cell activity has also been established (15). In the present study, depletion of NK cells or the elimination of STAT1-mediated signaling within host tissues abrogated the antitumor activity of IFN- $\alpha$. These results suggested that activation of STAT1 within NK cells was responsible for the prolonged survival associated with IFN- $\alpha$ administration. Furthermore, we were able to detect the presence of NK cells within the PECs of IFN-treated wild-type mice bearing B16F1 tumors. We found that STAT1-mice exhibited reduced splenocyte cytotoxic activity as compared with the NK-sensitive YAC1 and B16F1 cell lines in vitro. Lee et al. (15) examined basal NK cell cytotoxic activity in STAT1/- mice and found that although $S T A T 1^{-/-}$splenocytes exhibited normal levels of NK functional molecules (e.g., perforin and granzymes) and near-normal capacity for IFN- $\gamma$ production and antibody-dependent cellular cytotoxicity, these cells were unable to lyse an MHC class I-deficient target in vitro. STAT1-/- mice also failed to reject class I-deficient cells in vivo over a range of tumor inoculums in this study. Similar results were obtained in experiments with RAG1 $1^{-/}$STAT1/- mice (which fail to develop functional $\mathrm{T}$ and $\mathrm{B}$ cells), suggesting that STAT1 may be involved in the transmission of signals required for NK cell recognition of tumor targets (15). Thus, Jak-STAT signaling appears to be critical to the actions of NK cells both in their interactions with class I-deficient tumor cells and their elimination of established tumors after treatment with IFN- $\alpha$.

In summary, these results indicate that IFN- $\alpha$-mediated activation of STAT1 signaling in host tissues is sufficient to mediate an antitumor response in multiple murine models of malignant melanoma. Although there was evidence that tumor tissues were affected by the concentrations of IFN- $\alpha$ used in these experiments, it is apparent that transcription of STAT1-responsive genes within these malignant cells was not critical to the therapeutic actions of IFN- $\alpha$. These findings suggested that examination of STAT1 signaling in host immune effectors may provide new insights into the exact molecular targets of IFN- $\alpha$ and the determinants of IFN- $\alpha$ sensitivity and resistance. Further studies of STAT1 gene regulation within specific immune cell subsets is therefore warranted.

\section{Acknowledgments}

This work was supported by National Institutes of Health grants CA84402 and P30-CA16058 and by the Valvano Foundation for Cancer Research Award. G.B. Lesinski is a T32 NRSA Research Fellow (5 T32 CA90223-02). 
1. Kirkwood, J.M., Ibrahim, J.G., Sondak, V.K., Ernstoff, M.S., and Ross, M. 2002. Interferon alfa-2a for melanoma metastases. Lancet. 359:978-979.

2. Belardelli, F., Ferrantini, M., Proietti, E., and Kirkwood, J.M. 2002. Interferon-alpha in tumor immunity and immunotherapy. Cytokine Growth Factor Rev. 13:119-134.

3. Kirkwood, J.M., et al. 2000. High- and low-dose interferon alfa-2b in highrisk melanoma: first analysis of intergroup trial E1690/S9111/C9190. J. Clin. Oncol. 18:2444-2458.

4. Agarwala, S.S., and Kirkwood, J.M. 1995. Potential uses of interferon alpha 2 as adjuvant therapy in cancer. Ann. Surg. Oncol. 2:365-371.

5. Biron, C.A. 2001. Interferons alpha and beta as immune regulators - a new look. Immunity. 14:661-664.

6. Martin-Henao, G.A., et al. 2000. L-selectin expression is low on CD34+ cells from patients with chronic myeloid leukemia and interferon- $\alpha$ upregulates this expression. Haematologica. 85:139-146.

7. von Stamm, U., et al. 1993. Effects of systemic interferon-alpha (IFN-alpha) on the antigenic phenotype of melanoma metastases. EORTC Melanoma Group Cooperative Study No. 18852. Melanoma Res. 3:173-180.

8. Ezekowitz, R.A., Mulliken, J.B., and Folkman, J. 1992. Interferon alfa-2a therapy for life-threatening hemangiomas of infancy. N. Engl. J. Med. 326:1456-1463.

9. Slaton, J.W., Perrotte, P., Inoue, K., Dinney, C.P., and Fidler, I.J. 1999. Interferon-alpha-mediated down-regulation of angiogenesis-related genes and therapy of bladder cancer are dependent on optimization of biological dose and schedule. Clin. Cancer Res. 5:2726-2734.

10. Haque, S.J., and Williams, B.R. 1998. Signal transduction in the interferon system. Semin. Oncol. 25:14-22.

11. Leonard, W.J., and O'Shea, J.J. 1998. Jaks and STATs: biological implications. Annu. Rev. Immunol. 16:293-322.

12. Darnell, J.E., Jr., Kerr, I.M., and Stark, G.R. 1994. Jak-STAT pathways and transcriptional activation in response to IFNs and other extracellular signaling proteins. Science. 264:1415-1421.

13. Levy, D.E., Kessler, D.S., Pine, R., Reich, N., and Darnell, J.E., Jr. 1988 Interferon-induced nuclear factors that bind a shared promoter element correlate with positive and negative transcriptional control. Genes Dev. 2:383-393.

14. Vujanovic, N.L., Basse, P., Herberman, R.B., and Whiteside, T.L. 1996. Antitumor functions of natural killer cells and control of metastases. Methods. 9:394-408.

15. Lee, C.K., et al. 2000. Distinct requirements for IFNs and STAT1 in NK cell function. J. Immunol. 165:3571-3577.

16. Carson, W.E., et al. 1999. A fatal cytokine-induced systemic inflammatory response reveals a critical role for NK cells. J. Immunol. 162:4943-4951.

17. Carson, W.E., and Walker, M.J. 2000. Animal models of malignant melanoma. In Tumor models in cancer. B.A. Teicher, editor. Humana Press. Totowa, New Jersey, USA. 471-492.

18. Berkelhammer, J., Oxenhandler, R.W., Hook, R.R., Jr., and Hennessy, J.M 1982. Development of a new melanoma model in C57BL/6 mice. Cancer Res. 42:3157-3163

19. Durbin, J.E., Hackenmiller, R., Simon, M.C., and Levy, D.E. 1996. Targeted disruption of the mouse Stat 1 gene results in compromised innate immunity to viral disease. Cell. 84:443-450.

20. Bosma, G.C., Custer, R.P., and Bosma, M.J. 1983. A severe combined immunodeficiency mutation in the mouse. Nature. 301:527-530.

21. Sadowski, H.B., Shuai, K., Darnell, J.E., Jr., and Gilman, M.Z. 1993. A common nuclear signal transduction pathway activated by growth factor and cytokine receptors. Science. 261:1739-1744.

22. Ruff-Jamison, S., et al. 1994. Epidermal growth factor and lipopolysaccharide activate Stat 3 transcription factor in mouse liver. J. Biol. Chem. 269:21933-21935.

23. Cherry, S.R., Biniszkiewicz, D., van Parijs, L., Baltimore, D., and Jaenisch, R. 2000. Retroviral expression in embryonic stem cells and hematopoietic stem cells. Mol. Cell. Biol. 20:7419-7426.

24. Walter, M.J., Look, D.C., Tidwell, R.M., Roswit, W.T., and Holtzman, M.J 1997. Targeted inhibition of interferon-gamma-dependent intercellular adhesion molecule-1 (ICAM-1) expression using dominant-negative Stat1. J. Biol. Chem. 272:28582-28589.

25. Pear, W.S., Nolan, G.P., Scott, M.L., and Baltimore, D. 1993. Production of high-titer helper-free retroviruses by transient transfection. Proc. Natl. Acad. Sci. U. S. A. 90:8392-8396.

26. Fleisher, T.A., et al. 1999. Detection of intracellular phosphorylated STAT-1 by flow cytometry. Clin. Immunol. 90:425-430.

27. Hobart, M., Ramassar, V., Goes, N., Urmson, J., and Halloran, P.F. 1997. IFN-regulatory factor-1 plays a central role in the regulation of the expression of class I and II MHC genes in vivo. J. Immunol. 158:4260-4269.

28. Yang, C.H., et al. 2000. IFNalpha/beta promotes cell survival by activating NF-kappa B. Proc. Natl. Acad. Sci. U. S. A. 97:13631-13636.

29. Suzuki, K., et al. 1999. Activation of target-tissue immune-recognition molecules by double-stranded polynucleotides. Proc. Natl. Acad. Sci. U. S. A. 96:2285-2290
30. Bluyssen, H.A., et al. 1994. Structure, chromosome localization, and regulation of expression of the interferon-regulated mouse Ifi54/Ifi56 gene family. Genomics. 24:137-148.

31. Hassouna, N., Michot, B., and Bachellerie, J.P. 1984. The complete nucleotide sequence of mouse $28 \mathrm{~S}$ rRNA gene. Implications for the process of size increase of the large subunit rRNA in higher eukaryotes. Nucleic Acids Res. 12:3563-3583.

32. Fleischmann, C.M., Stanton, G.J., and Fleischmann, W.R., Jr. 1996. Enhanced in vivo sensitivity of in vitro interferon-treated B16 melanoma cells to CD8 cells and activated macrophages. J. Interferon Cytokine Res. 16:805-812.

33. Shrayer, D.P., Bogaars, H., Wolf, S.F., Hearing, V.J., and Wanebo, H.J. 1998. A new mouse model of experimental melanoma for vaccine and lymphokine therapy. Int. J. Oncol. 13:361-374.

34. Fehniger, T.A., Carson, W.E., Mrozek, E., and Caligiuri, M.A. 1997. Stem cell factor enhances interleukin-2-mediated expansion of murine natural killer cells in vivo. Blood. 90:3647-3653.

35. Tessitore, A., et al. 1998. Two gamma-interferon-activation sites (GAS) on the promoter of the human intercellular adhesion molecule (ICAM-1) gene are required for induction of transcription by IFN-gamma. Eur. J. Biochem. 258:968-975.

36. Kurosawa, S., et al. 1995. Early-appearing tumour-infiltrating natural killer cells play a crucial role in the generation of anti-tumour T lymphocytes. Immunology. 85:338-346.

37. Liao, S.K., Kwong, P.C., Khosravi, M., and Dent, P.B. 1982. Enhanced expression of melanoma-associated antigens and beta 2-microglobulin on cultured human melanoma cells by interferon. J. Natl. Cancer Inst. 68:19-25.

38. Navarro, S., Colamonici, O.R., and Llombart-Bosch, A. 1996. Immunohistochemical detection of the type I interferon receptor in human fetal, adult, and neoplastic tissues. Mod. Pathol. 9:150-156.

39. Carson, W.E. 1998. Interferon-alpha-induced activation of signal transducer and activator of transcription proteins in malignant melanoma. Clin. Cancer Res. 4:2219-2228.

40. Pansky, A., et al. 2000. Defective Jak-STAT signal transduction pathway in melanoma cells resistant to growth inhibition by interferon-alpha. Int. J. Cancer. 85:720-725.

41. Wong, L.H., Hatzinisiriou, I., Devenish, R.J., and Ralph, S.J. 1998. IFNgamma priming up-regulates IFN-stimulated gene factor 3 (ISGF3) components, augmenting responsiveness of IFN-resistant melanoma cells to type I IFNs. J. Immunol. 160:5475-5484.

42. Kaplan, D.H., et al. 1998. Demonstration of an interferon gammadependent tumor surveillance system in immunocompetent mice. Proc. Natl. Acad. Sci. U. S. A. 95:7556-7561.

43. Huang, S., Bucana, C.D., Van Arsdall, M., and Fidler, I.J. 2002. Stat1 negatively regulates angiogenesis, tumorigenicity and metastasis of tumor cells. Oncogene. 21:2504-2512.

44. Gil, M.P., et al. 2001. Biologic consequences of Stat1-independent IFNsignaling. Proc. Natl. Acad. Sci. U. S. A. 98:6680-6685.

45. Wong, A.H., et al. 1997. Physical association between STAT1 and the interferon-inducible protein kinase PKR and implications for interferon and double-stranded RNA signaling pathways. EMBO J 16:1291-1304

46. Ramana, C.V., et al. 2001. Stat1-independent regulation of gene expression in response to IFN-gamma. Proc. Natl. Acad. Sci.U. S. A. 98:6674-6679.

47. Uddin, S., et al. 1999. Activation of the p38 mitogen-activated protein kinase by type I interferons. J. Biol. Chem. 274:30127-30131.

48. Deb, A., Haque, S.J., Mogensen, T., Silverman, R.H., and Williams, B.R. 2001. RNA-dependent protein kinase PKR is required for activation of NF-kappa B by IFN-gamma in a STAT1-independent pathway. J. Immunol. 166:6170-6180.

49. Moretti, S., et al. 2001. Serum imbalance of cytokines in melanoma patients. Melanoma Res. 11:395-399.

50. Lauerova, L., et al. 2002. Malignant melanoma associates with Th1/Th2 imbalance that coincides with disease progression and immunotherapy response. Neoplasma. 49:159-166.

51. Ueda, M., et al. 1986. Time-dependent suppression of melanoma metastases and natural killer cell activation by interferon. Arch. Dermatol. Res. 278:329-334.

52. Markovic, S.N., and Murasko, D.M. 1991. Role of natural killer and T-cells in interferon induced inhibition of spontaneous metastases of the B16F10L murine melanoma. Cancer Res. 51:1124-1128.

53. Hersey, P., et al. 1986. Immunological effects of recombinant interferon alfa-2a in patients with disseminated melanoma. Cancer. 57:1666-1674.

54. Golub, S.H., Dorey, F., Hara, D., Morton, D.L., and Burk, M.W. 1982. Systemic administration of human leukocyte interferon to melanoma patients. I. Effects on natural killer function and cell population. J. Nath. Cancer Inst. 68:703-710.

55. Seo, N., Tokura, Y., Furukawa, F., and Takigawa, M. 1998. Down-regulation of tumoricidal $\mathrm{NK}$ and $\mathrm{NK} \mathrm{T}$ cell activities by MHC Kb molecules expressed on Th2-type gammadelta $\mathrm{T}$ and alphabeta $\mathrm{T}$ cells coinfiltrating in early B16 melanoma lesions. J. Immunol. 161:4138-4145. 